\title{
Menores y publicidad de juegos de azar en internet: nuevos formatos, contenidos publicitarios y retos en la protección de los menores
}

\author{
Minors and internet gambling advertising: \\ new formats, advertising content, and \\ challenges in protecting minors
}

\author{
Esther Martínez-Pastor; Ricardo Vizcaíno-Laorga
}

Cómo citar este artículo:

Martínez-Pastor, Esther; Vizcaíno-Laorga, Ricardo (2021). "Menores y publicidad de juegos de azar en internet: nuevos formatos, contenidos publicitarios y retos en la protección de los menores". Profesional de la información, v. 30, n. 4, e300420.

https://doi.org/10.3145/epi.2021.jul.20

Artículo recibido el 23-12-2020

Aceptación definitiva: 22-03-2021

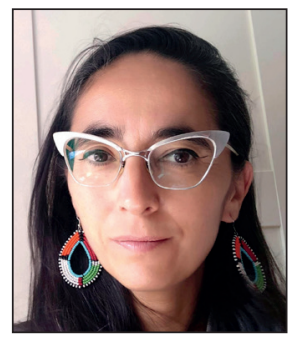

\author{
Esther Martínez-Pastor $\bowtie$ \\ https://orcid.org/0000-0002-2861-750X \\ Universidad Rey Juan Carlos \\ Facultad de Ciencias de la Comunicación \\ Camino del Molino, 5 \\ 28943 Fuenlabrada (Madrid), España \\ esther.martinez.pastor@urjc.es
}

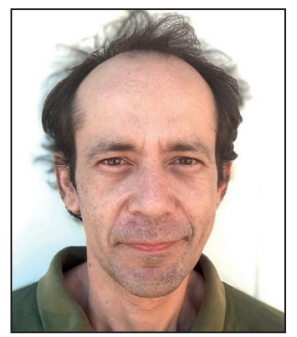

Ricardo Vizcaíno-Laorga https://orcid.org/0000-0003-3164-8099

Universidad Rey Juan Carlos

Facultad de Ciencias de la Comunicación Camino del Molino, 5

28943 Fuenlabrada (Madrid), España

ricardo.vizcaino@urjc.es

\section{Resumen}

El objetivo de este artículo es conocer los nuevos formatos y contenidos publicitarios empleados en vídeos sobre juegos de azar en internet, y si estos formatos se encuentran regulados en la normativa actual o pueden suponer un riesgo para los menores. Se ha llevado a cabo un análisis de contenido de 50 vídeos de YouTube (un total de 574 minutos) a partir del cribado previo de 500 unidades, así como una observación participante de otros canales y plataformas de internet. Se ha trabajado con una muestra de conveniencia obtenida mediante búsqueda sistemática (palabras clave) y su consecuente bola de nieve. Entre los resultados más relevantes se destaca que la actual normativa aprobada, el Real decreto 958/2020, de 3 de noviembre, de comunicaciones comerciales de las actividades de juego, no tiene en cuenta contenidos publicitarios como tutoriales o apuestas deportivas, ni formatos ni plataformas diferentes.

\section{Palabras clave}

Juegos de azar online; Internet; Formatos; Menores; Adolescentes; Pronosticadores; Normativa; Publicidad; Cajas sorpresa; YouTube.

\footnotetext{
Abstract

The aim of this article is to describe the new formats and advertising content used in videos related to gambling on the Internet and minors, and whether these formats are currently regulated or may pose an additional risk to minors. For this study, content analysis of 50 YouTube videos (a total of 574 minutes) was carried out, based on a previous screening of 500 units. We worked with a convenience sample obtained through a systematic search (keywords) followed by the snowball method. Among the most relevant results, it is worth mentioning that the currently approved regulation, the Spanish Royal decree on commercial communications in gaming activity, does not consider advertising content such as tutorials or sports bets, nor various formats or social networks.
}

Keywords

Gambling; Internet; Formats; Minors; Adolescents; Young people; Tipsters; Regulations; Advertising; Loot boxes; YouTube. 


\section{Introducción}

\subsection{El juego de azar en Europa y en España}

El juego de azar online se caracteriza porque concurren azar y riesgo económico a través de una plataforma en la Red (García-Ruiz; Buil-Gazol; Solé-Moratilla, 2016). Los ingresos brutos de este sector se incrementan aproximadamente un $7 \%$ anual (European Gaming and Betting Association, 2020). No obstante, durante 2020 el juego de azar global (físico y online) tuvo una caída del 23\%: de 98.600 millones de euros en 2019 a 75.900 millones en 2020, debido a la cancelación de los principales deportes europeos y al cierre de los establecimientos físicos por la crisis sanitaria de la Covid-19 (European Gaming and Betting Association, 2020; Lock, 2020).

En 2019, los países europeos con mayores ingresos brutos por apuestas fueron Italia (18.100 millones) y Alemania (14.300 millones), seguidos por Francia (12.200 millones) y España (8.900 millones) (Lock, 2020). Se prevé que los países con mayor crecimiento sean Alemania, España, Francia e Italia. El sector de juego online también crece constantemente y se espera que alcance el $33,6 \%$ de los ingresos brutos de los juegos de azar en Europa para 2025 (European Gaming and Betting Association, 2020; Lock, 2020).
Durante 2020 el juego de azar global (físico y online) tuvo una caída del $23 \%$ : de 98.600 millones de euros en 2019 a 75.900 millones en 2020, debido a la cancelación de los principales deportes europeos y al cierre de los establecimientos físicos por la crisis sanitaria de la Covid-19

En España, el juego online tuvo un gross gaming revenue (margen de juego o ingresos brutos) de 747 millones de euros en 2019 , un aumento de un 6,95\% respecto a 2018, según un informe sobre el sector del juego online de la Dirección General de Ordenación del Juego (2019). En acciones de marketing se invirtieron 328 millones de euros en 2018, de los cuales 168 millones se dedicaron a publicidad -un incremento del 61\% respecto al año 2017 (103 millones)- (Dirección General de Ordenación del Juego, 2018a). Esto indica que es un nicho de mercado muy interesante para la presencia de comunicaciones comerciales.

\subsection{Juegos de azar, menores e internet: consumidores, productores y su regulación}

Según el informe de 2018 sobre perfiles de jugadores (Dirección General de Ordenación del Juego, 2018b) el 27\% de los jugadores activos son jóvenes de entre 18-25 años, lo que supone 397.570 personas con un gasto anual de algo más de 75 millones de euros al año (189€/persona/año). Y según el Estudio sobre prevalencia, comportamiento y características de los usuarios de juego de azar (Dirección General de Ordenación del Juego, 2016) el 14\% de las personas han jugado juegos de azar antes de los 18 años.

El consumo de medios digitales por parte de menores y jóvenes es cada vez mayor (Orús, 2021; Ofcom, 2019; PWC, 2019; Holloway; Green; Livingstone, 2013): el 95\% lo hace desde los móviles, y los menores entre 5 y 15 años invierten más de 15 horas a la semana en el consumo online (Anderson; Jiang, 2018; Ofcom, 2020). Los contenidos generados por influencers son los preferidos entre los menores (Wunderman Thompson, 2019). De hecho, en España la inversión de publicidad en 2019 en influencers fue de 61,8 millones de euros (Infoadex, 2020). Asimismo, los estudios de Inversión publicitaria en medios digitales (IAB; PWC, 2019) y Redes Sociales (IAB, 2019b) indican que se destinó un 25,6 \% de la inversión total de publicidad digital a las redes sociales, lo que equivale a 806,4 millones de un total de 3.150 millones de euros. Y en cuanto a la publicidad digital dirigida a menores se prevé que en 2021 aumente en un $45 \%$ respecto a 2018 (Martínez-Pastor et al., 2020).

En el sector de los juegos de azar online está habiendo una captación de nuevos jugadores jóvenes en la franja de 18 a 25 años, y públicos más jóvenes a través de influencers que, ocasionalmente, promocionan juegos de azar como loot boxes (Hidalgo-Cerezo, 2019), siendo más propenso a estos juegos el género masculino $(89,71 \%)$ que el femenino (10,29\%) (Dirección General de Ordenación del Juego, 2018b). En ocasiones, jóvenes youtubers generan contenidos ad hoc sobre la temática de juegos de azar vinculados a marcas. Se trata de contenidos que a su vez constituyen por sí mismos comunicaciones comerciales o que incluyen publicidad convencional (Pareja, 2020; Hidalgo-Cerezo, 2019; Pérez-Camarero; Alcalá-Revilla; Pérez-Cañellas, 2018; García-Ruiz; Buil-Gazol; Solé-Moratilla, 2016). Y así cada vez hay más formatos publicitarios en el medio digital que favorece que numerosas marcas estén presentes entre nuestros menores (IAB, 2019a; Taylor, 2017; Craig; Cunningham, 2017; Cauberghe et al., 2016; Ramos-Serrano; Herrero-Diz, 2016; Wu, 2016). Asimismo la publicidad nativa que vaticinaron Campbell y Marks (2015) es ya muy recurrente en YouTube. Su contenido es semejante a contenidos de entretenimiento, sin ser intrusiva (Tur-Viñes; Núñez-Gómez; Martínez-Pastor, 2019; Hudders et al., 2016).

Con esta situación la Unión Europea tiene entre sus principales desafíos la protección de los menores en los juegos de azar online debido a la facilidad del acceso que los niños tienen desde cualquier dispositivo, así como por la publicidad integrada en los contenidos generados por los usuarios que pueda aparecer sin ser claramente diferenciada y no estar controlada mediante verificación de edad u otros sistemas (Hörnle et al., 2018).
En España, el juego online tuvo un gross gaming revenue (margen de juego o ingresos brutos) de 747 millones de euros en 2019 , un aumento de un $6,95 \%$ respecto a 2018 
Por todas estas razones, esta investigación se ha centrado en los juegos y actividades de azar dirigidos a jóvenes en una de las plataformas de intercambio de vídeo más utilizada por este público, YouTube (Ofcom, 2019), si bien se indaga sobre la presencia de los juegos de azar en otras plataformas y canales de internet.

El propósito es identificar los nuevos formatos publicitarios empleados en vídeos relacionados con juegos de azar en internet, de acuerdo con la clasificación realizada el por el IAB (2019a), y a partir de otros identificados por exclusión frente a formatos estandarizados. Además, se plantea si estos formatos se encuentran regulados en la normativa actual o pueden suponer un riesgo añadido para los menores, como apunta el trabajo de Cauberghe et al. (2016).

\section{Estado de la cuestión-estudio previos}

\subsection{Jóvenes y menores: percepción del riesgo y consecuencias}

Los estudios relacionados con la publicidad, el juego de azar y menores se centran en conocer cómo se acerca la publicidad a los niños y el grado de persuasión que ésta puede tener en los menores para que empiecen a jugar. De acuerdo con García-Ruiz, Buil-Gazol y Solé-Moratilla (2016) los trabajos iniciales en torno a esta temática se han llevado a cabo en Australia, Canadá, Estados Unidos y Reino Unido, con estudios centrados en los menores y los riesgos de los juegos de azar. Las investigaciones de Splevins et al. (2010) o de McBride y Derevensky (2012) han trabajado en este sentido. Ambos estudios se centraron en conocer el riesgo de los juegos de azar en los adolescentes y universitarios. Los resultados mostraron que juegan más los varones jóvenes y que la mayoría de las veces no son capaces de comprender que pueden tener un problema serio. El trabajo de Derevensky et al. (2010), realizado a través de encuestas a jóvenes, mostró que estos eran conscientes de los riesgos asociados al juego y creían que los mensajes publicitarios no eran para captar nuevos jugadores sino para mantener a los que ya jugaban.

Por su parte, García-Ruiz, Buil-Gazol y Solé-Moratilla (2016) centran su trabajo en el concepto del juego responsable en los menores y los juegos de azar. Y Carbonell-Vayá y Montiel-Juan (2013) llevaron a cabo un estudio cualitativo y cuantitativo en menores, mediante entrevistas y encuestas, sobre la percepción de los jóvenes de entre 12 y 18 años y los juegos de azar online.

Se han llevado a cabo diversos trabajos en Europa:

- centrado en Finlandia, Raisamo et al. (2013) analizaron la frecuencia de los juegos de azar y los daños relacionados con el juego. Los resultados más relevantes fueron que el daño más frecuente entre los jugadores era sentirse culpable o avergonzado, así como problemas en las relaciones y alteraciones del ritmo diario;

- en Islandia, Olason et al. (2011) obtuvieron resultados similares a los anteriores: los jóvenes varones son más propicios a estos juegos y más a través de medios digitales;

- en Italia, Cosenza y Nigro (2015) constataron que el juego tiene como consecuencia asociadas distorsiones cognitivas y que puede mermar las capacidades en el futuro.

Posteriormente ha habido una mayor proliferación de trabajos, muchos de ellos centrados en jóvenes y menores. Conviene destacar el estudio de Newall et al. (2019) quienes realizan una revisión completa de la bibliografía sobre la publicidad del juego de 2014 a 2018, entre las que se destaca el análisis de la Gambling Commission de Reino Unido (2017). En él se indica que el 10\% de los menores de 11 a 16 años siguen al menos una compañía de juegos de azar en los medios sociales. Asimismo, el trabajo de Newall et al. (2019) sostiene que los menores están expuestos a los mensajes comerciales del juego de azar online, si bien la escasez de trabajos en torno a este asunto no permite identificar el alcance y las frecuencias de este colectivo en torno a la actividad del juego. Se han identificado otros trabajos como el de Kim et al. (2017) en el que se observa que los juegos de casino social y su publicidad asociada eran un punto de entrada a los juegos de azar online.

Es la misma idea recogida por Abarbanel et al. (2017), quienes estudiaron la exposición de la juventud a la publicidad de los casinos sociales en el contexto australiano.

Cases-Méndez et al. (2018) buscaron conocer la percepción del juego online de los jóvenes a partir de los 18 años y poner en alerta el acceso prematuro de los menores a los juegos online a través de los dispositivos que tienen a su alcance, sin profundizar en este tema.

Chóliz y Lamas (2017) investigaron la posible adicción de los menores de 18 con los juegos de azar y la necesidad de que la normativa se ajustara a la realidad. Hernández-Ruiz (2020) se centra en el artículo 8 de la Ley de regulación del juego y en la necesidad de mejorar la responsabilidad social corporativa por parte de los operadores que operan en la Web en acciones preventivas, de sensibilización, intervención, control y de reparación.

Otros estudios como el de Thomas et al. (2018) se enfocaron en conocer el recuerdo de la publicidad de azar y si se respetan las restricciones para proteger a los menores. Los resultados mostraron que las restricciones se suelen 
infringir. Por su parte Parrado-González y León-Jariego (2020) focalizaron sus esfuerzos en conocer qué estrategias publicitarias se llevaron cabo para influenciar en el comportamiento de los menores, además de analizar el propio perfil del menor. Así se detectó que los niños con un mayor arraigo familiar se enganchaban menos.
Según la Gambling Commission del Reino Unido (2017), el 10\% de los menores de 11 a 16 años siguen al menos una compañía de juegos de azar en los medios sociales

\subsection{Prevención de riesgos}

En cuanto a trabajos que centran su interés en la detección, evaluación y prevención de riesgos asociados al juego en menores cabe destacar la investigación llevada a cabo por Caselles-Cámara, Cabrera-Perona y Lloret-Irles (2018) en la que analizan la edad más adecuada para aplicar los programas de prevención. Realizan una encuesta a 2.716 estudiantes de Educación Secundaria Obligatoria (ESO) y Bachillerato. Como principales resultados se desataca que entre los 15 y 17 años hay un notable incremento de la frecuencia de juego, especialmente entre chicos, y promovida por la accesibilidad online. Por este motivo, los investigadores sugieren que la prevención debería dirigirse preferentemente a menores de 15 años y tener mucha atención en la accesibilidad y la frecuencia de juego en el caso online. En esta línea, Chóliz y Lamas (2017) y Lamas (2017) sostienen que un problema añadido a los riesgos de los juegos de azar es el aumento masivo de centros de apuestas y webs online, que fomenta la adicción. El objetivo es prevenir los riesgos asociados a los juegos de azar en los menores como evidencian Calado, Alexandre y Griffiths (2017) mediante una revisión bibliográfica sobre este tema desde el año 2000; o el trabajo de González-Roz et al. (2016), quienes sostienen que un ambiente familiar con problemas aumenta el consumo del juego de azar como refugio del menor después de encuestar a 1.313 de entre 14 y 18 en España.

\subsection{Juegos de azar: nuevos agentes, nuevos modelos y su regulación}

También se ha investigado sobre nuevos juegos de azar dirigidos a jóvenes y menores. Gardner y Lehnert (2016) se centraron en los creadores de contenidos, en la variedad de los propios contenidos y en la integración de marcas en los mismos, explicando las estrategias llevadas a cabo. También es el caso del trabajo del Instituto de la Juventud (Injuve), en el que se analizaban nuevas figuras que promueven al juego entre los jóvenes, como los tipsters en plataformas online (Pérez-Camarero; Alcalá-Revilla; Pérez-Cañellas, 2018), y el estudio de Miller, Krasodomski-Jones y Smith (2016) que investigaron sobre el fenómeno de los tipsters (pronosticadores, personas que ofrecen tips o pistas sobre posible vencedores) en Twitter que comparten información, ofertas y oportunidades relacionadas con los juegos de azar.

En las apuestas deportivas, el tipster es quien escribe pronósticos sobre eventos deportivos para que otros jugadores puedan hacer una apuesta con más garantía de éxito. Tienen mucha presencia entre los jóvenes: la mayoría de los tipsters se rodean de famosos y promueven un alto estilo de vida fruto de sus apuestas, tal y como describe la bibliografía (Pareja, 2020). Son profesionales y suelen regalar o vender sus pronósticos siempre que sean empleados en una casa de apuestas en particular con la que previamente ha negociado el precio de su consejo.

"El tipster se lleva una comisión, y la casa de apuestas gana algo de tráfico y el depósito/apuestas de nuevos jugadores" (Pérez-Camarero; Alcalá-Revilla; Pérez-Cañellas, 2018, p. 48).

Pareja (2020) sostiene que hay tipsters que sólo aconsejan cómo ganar dinero a las casas de apuestas sin tener acuerdos de colaboración con el sector del juego.

Por su parte Hidalgo-Cerezo (2019) se centra en la modalidad de los juegos de azar de las cajas sorpresa (loot boxes o cajas botín) dirigida a menores y jóvenes, y la comercialización realizada para este target. En este sentido, Griffiths (2018) reflexiona sobre si las cajas sorpresa son una forma de juego de azar, llegando a la conclusión de que lo son porque los "premios" ganados son a menudo, en términos económicos, mucho más bajos que el precio pagado. Loot boxes

"se refiere o designa a un tipo de consumible virtual, de naturaleza puramente digital, y cuyo contenido se compone de una selección aleatoria de items. Normalmente se presenta dentro de un contexto de juego de competición" (Hidalgo-Cerezo, 2019, p. 38; Netherlands Gambling Authority, 2018).

Las hay de tres tipos (Hidalgo-Cerezo, 2019, p. 39):

- como recompensa al alcanzar un ítem del juego;

- mediante el pago en una moneda virtual como parte del juego como potenciadores o armas, entre otros;

- pequeñas transacciones de dinero real a cambio de premios en las cajas sorpresa.

El sistema consiste en lo siguiente:

1. El usuario realiza un depósito en la plataforma y paga por abrir cajas en el momento que elija.

2. El usuario sabe de antemano cuáles son los productos que puede ganar en esas cajas. 
3. El juego consiste en que se mueve una ruleta y el usuario decide cuándo pararla.

4. Aparece el producto obtenido y el usuario tiene dos opciones: quiere recibirlo o no quiere ese producto y tiene la posibilidad de venderlo a la empresa de las cajas sorpresa y seguir jugando.

5. Siempre se gana un producto.

Habitualmente los promotores de la "caja sorpresa" se ponen en contacto con un youtuber y le ofrecen una cantidad de dinero y un premio de los que se ofrecen. Y posteriormente, el youtuber realizará un vídeo unboxing cuando le llegue el producto obtenido. Esta estrategia anima a otros usuarios a participar (Tio Shur). Según Hidalgo-Cerezo este juego fomenta

"un caldo de cultivo ideal para desatar mecánicas de compulsión, entendidas como impulso interno dirigido a probar suerte a cambio de una cantidad pequeña de dinero. La repetición de estas conductas puede llevar a pérdidas económicas notables (...) y lo que es más importante, introduce comportamientos asociados al juego que se encuentra al alcance de menores, siendo este un grupo vulnerable y de alto riesgo" (Hidalgo-Cerezo, 2019, p. 39).

Se promueve el juego de azar y se utilizan mecanismos gráficos, auditivos y sociales como gancho, utilizados en las máquinas de azar para generar

“deseo, emoción y, eventualmente, adicción” (Hidalgo-Cerezo, 2019, p. 45).

Buil, Solé-Moratilla y García-Ruiz (2015) llevaron a cabo un análisis de la regulación de la publicidad en los juegos de azar centrado en la protección de los menores al consumo de juegos de azar online. Pusieron de manifiesto que la regulación debería proteger mejor al menor de la publicidad. Este estudio lo completó posteriormente Solé-Moratilla (2019), que de una manera crítica sostiene que el marco jurídico actual presenta carencias en relación con los menores y la actividad del juego, y no proteje a este colectivo especialmente vulnerable por su edad.

García-Rodríguez (2017) cree que la Administración Pública debería actuar más eficazmente ante conductas publicitarias ilícitas, como así describe en su tesis sobre la regulación de la publicidad en los juegos de azar en España.

En definitiva, estos estudios abren un claro camino para investigar las nuevas formas de comunicación comercial de la actividad de los juegos de azar dirigidos a los jóvenes y menores. Tal y como sostiene Busby (2017) la exposición de este colectivo a la publicidad online en los medios sociales y plataformas de la actividad del juego es una prioridad de investigación futura.

\section{Marco normativo relativo a la publicidad de juegos de azar en Internet}

No existe una regulación europea específica sobre los juegos de azar. La UE permite que cada país regule esta actividad a nivel nacional, generando una normativa fragmentada en los diferentes países comunitarios (Hörnle et al., 2018). Solamente se recoge en algunos artículos, como en:

- Directiva de servicios de comunicación audiovisual;

- Directiva sobre prácticas comerciales desleales;

- Directiva sobre protección de datos;

- Directiva sobre privacidad y comunicaciones electrónicas.

De manera que la regulación se ha hecho de forma desigual: países como Reino Unido, Francia, Italia y España han sido los primeros en regular esta actividad, seguidos de otros como Dinamarca, Portugal, Rumanía, República Checa y Holanda (Pérez-Camarero; Alcalá-Revilla; Pérez-Cañellas, 2018).

En España, la actual norma del juego de azar está regulada por:

- Ley 13/2011, de 27 de mayo, de regulación del juego (LRJ) (España, 2011);

- Real decreto 958/2020, de 3 de noviembre, de comunicaciones comerciales de las actividades del juego (en adelante RDCCAJ) (España, 2020a);

- Código de conducta sobre comunicaciones comerciales de las actividades de juego de 2019 (CCCCAJ).

Aquí nos centraremos en el RDCCAJ, que se ha impulsado por la necesidad de afrontar el vertiginoso desarrollo del mercado del juego de azar online, por los cambios estructurales en la configuración del juego, el aumento de nuevos operadores y el incremento de la inversión de la publicidad (especialmente en el juego de azar online). El RDCCAJ también surge para dotar de mayor protección de los consumidores ( $y$, en especial, de los menores) así como para impulsar las acciones preventivas de sensibilización, prevención y control de la salud pública en el ejercicio de las actividades del juego. El objetivo último del RDCCAJ es desarrollar la Ley de regulación de juego (España, 2011) (en una línea similar al Código de conducta sobre comunicaciones comerciales de las actividades de juego de 2019) en lo referente a las condiciones en las que los operadores de juego pueden hacer publicidad, patrocinio, promoción o cualquier otra forma de comunicación comercial de su actividad. El RDCCAJ considera comunicación comercial 
"cualquier forma de actividad publicitaria difundida por cualquier medio o soporte, destinada a promocionar, de manera directa o indirecta, las actividades de juego (...) o las entidades que las realizan" (art. 3, g).

Se excluyen:

"la retransmisión de sorteos de juego, así como la difusión puramente informativa de sus resultados".

Se elaboran las condiciones bajo las que deben llevarse a cabo las políticas de juego responsable y protección de consumidores de los operadores de juego.

EI RDCCAJ (art. 2) regula que el operador de juego es la persona física o jurídica que se encuentre habilitada, legalmente o mediante licencia o autorización, para el ejercicio de actividades de juego de ámbito estatal. Es decir, son aquellos que han obtenido título habilitante para el desarrollo de actividades de juego online (art. 3 RDCCAJ). Se define quiénes son los servicios relacionados con las comunicaciones comerciales de una manera más amplia que en la LRJ, como son las redes publicitarias, los servicios de comunicación audiovisual y los servicios de intercambio de vídeos a través de plataformas (art. 3).

En relación con las comunicaciones comerciales, el RDCCAJ incluye la identificación (art. 7), veracidad (art. 8) y la responsabilidad social (art. 9) al igual que recoge el CCCCAJ (art. 3, 4 y 5) que la actual LRJ no aborda. EI RDCCAJ indica que toda comunicación comercial debe ser identificable y reconocible (el usuario tiene que saber que se trata de publicidad). Se debe emplear una fórmula similar a "publicidad", "publi" (o bien la comunicación comercial se inserte en bloques o espacios publicitarios claramente identificables como tales por el usuario).

Toda comunicación comercial debe ser veraz y no puede aparecer información falsa para no inducir a error a sus destinatarios. También se apela a la responsabilidad social sin banalizar sobre las consecuencias de la actividad del juego. Para Hidalgo-Cerezo (2019) el juego responsable es aquel en el que hay transparencia entre el operador y el jugador :

- las dos partes conocen las reglas, mecanismos y probabilidades del juego;

- se informa claramente que este puede convertirse en un problema de salud y que es un entretenimiento y como tal no debe invertirse el dinero del que no se dispone.

Se prohíbe la comunicación comercial que:

- asocie el juego con actividades ilícitas o con actividades que causen daños económicos, sociales o emocionales;

- desacrediten a quien no juegue;

- desvalorice el esfuerzo en comparación con el juego;

- apele expresamente a que comparta el mensaje previsto en la comunicación comercial;

- utilicen representaciones gráficas del dinero o de productos de lujo;

- inciten a comportamientos violentos, discriminatorios o humillantes.

La LRJ (art. 8) y el CCCCAJ (art. 6) apelan al juego responsable entendiendo esta actividad como un fenómeno complejo en el que se deben realizar acciones preventivas de sensibilización, intervención y control, así como reparación de los efectos negativos producidos. EI RDCCAJ (art. 10.3.) plantea la obligatoriedad de incluir mensajes visuales de advertencia ("si juegas, sé responsable") claramente visibles en toda la comunicación (u ocupar toda la imagen dos segundos al final) o verbales (dos segundos al final).

En relación con los menores en el RDCCAJ (art. 11) y el CCCCAJ (art. 7) se prohíbe expresamente que las comunicaciones comerciales vayan dirigidas a este público ya sea de forma directa o indirecta. Se prohíbe que:

- inciten directa o indirectamente a menores de edad a la práctica del juego, por sí mismos o mediante terceras personas;

- resulten, por su contenido o diseño, racional y objetivamente aptas para atraer la atención o el interés particular de los menores de edad, incluyendo las mascotas de marca o sintonías destinadas específica o principalmente a menores de edad;

- exploten la especial relación de confianza que los menores de edad depositan en sus padres, profesores, u otras personas;

- utilicen la imagen, voz u otras características inherentes a los menores de edad o a personas caracterizadas para parecer menores de edad;

- presenten la práctica del juego como una señal de madurez o indicativa del paso a la edad adulta;

- se difundan o emplacen en medios, programas o soportes, cualquiera que éstos sean, destinados específica o principalmente a menores de edad;

- se inserten en aplicaciones, webs, o contenidos digitales dirigidos específica o principalmente a menores de edad, o bien junto a vínculos de webs destinadas a ese mismo público;

- además, las comunicaciones comerciales deberán incluir la advertencia de que los menores de edad no podrán participar en actividades de juego, tipo "menores no", "+18” o similar. 
Puede ser de forma gráfica u oral, pero en ambos casos la advertencia será claramente visible y deberá aparecer siempre como mínimo durante dos segundos. Actualmente la normativa en nuestro país protege a los menores de los juegos de azar: LRG (art. 6.2a) y prohíbe en la RDCCAJ (art. 11) y el CCCCAJ (art. 7) expresamente que las comunicaciones comerciales vayan dirigidas a este público ya sea de forma directa o indirecta (Buil; Solé-Moratilla; García-Ruiz, 2015, p. 201). Además de ser una preocupación para la Unión Europea que en 2014 dictó la Recomendación 2014/478/UE relativa a la protección de los consumidores y, en particular, de los menores, frente al juego online (Hidalgo-Cerezo, 2019).

En cuanto a la adecuación de ciertos juegos potencialmente relacionados con menores, como las cajas sorpresa, para algunos su regulación ya estaría recogida en la actual normativa LRJ (art. 2) y no estaría en un limbo legal (como afirman otros) en tanto que se arriesgan

"cantidades de dinero u objetos económicamente evaluables en cualquier forma, sobre resultados futuros e inciertos" (art. 2 de la Ley del juego),

entran dentro de ámbito de aplicación, mientras que otros juristas consideran que

“las leyes son de 2011 por lo que no incluye este tipo de juego 'online', es el problema de que todo avance tan rápido" (Cid, 2019).

Si se comparan los rasgos de este tipo de juego con los que contempla el artículo 3 apartado a. de la LRJ, también se puede ver en ellos que coincide con la definición de "Juego": se arriesga dinero, depende del azar y los premios son en especie (secundariamente posibilidad de cobro en metálico). En cualquier caso, su presencia en YouTube es relevante y en ocasiones el perfil se dirige más hacia un público adolescente-joven que hacia un público joven-adulto.

Actualmente también se está discutiendo la legalidad de estas cajas sorpresas en algunos países de la UE, Bélgica y Países Bajos (Netherlands Gambling Authority, 2018) las han prohibido por considerarlas ilegales, mientras que otros países comunitarios (Alemania, Suecia y Francia) las están discutiendo por su parecido con la dinámica del juego de azar de las "tragaperras" (Hidalgo-Cerezo, 2019). Por este motivo, llama poderosamente la atención que el RDCCAJ no aproveche esta discusión y regule esta realidad especificando este juego o protegiendo a los menores.

\section{Hipótesis y objetivos}

\subsection{Hipótesis}

Los formatos y contenidos de promoción online de actividades de juego son diferentes a los convencionales y ponen en riesgo a los menores y jóvenes, al no ajustarse a la normativa actual.

\subsection{Objetivo principal}

Identificar nuevos formatos y contenidos publicitarios para la promoción de juegos de azar y valorar su impacto-riesgo entre menores y jóvenes.

\subsection{Objetivos secundarios}

OS1: Identificar nuevos formatos publicitarios en plataformas de vídeo compartido (YouTube).

OS2: Caracterizar el perfil de los vídeos, sus protagonistas y su target.

OS3: Localizar otros canales/medios/plataformas para la difusión de juegos de azar en internet.

OS4: Identificar nuevos contenidos de juegos de azar en internet especialmente dirigidos a jóvenes y menores.

OS5: Valorar el impacto que los nuevos formatos publicitarios en internet podrían tener entre menores y jóvenes a la vista de la legislación vigente.

\section{Metodología}

Para este estudio se ha realizado un cribado de 500 vídeos de YouTube para tomar una muestra final de 574 minutos (análisis de contenido de 50 vídeos). Se ha trabajado con una muestra de conveniencia obtenida mediante búsqueda sistemática (palabras clave) y su consecuente bola de nieve. La muestra resultante abarca el período del 23/11/2016 al 06/05/2000. Con ello se cubren los objetivos OS1 y OS4.

Para el análisis de contenido, uno de los principales retos ha sido delimitar las unidades muestrales. Como sucede en otros estudios (Martínez-Pastor et al., 2020) la especificidad de la temática a tratar (en este caso juegos de azar/apuestas) impide disponer de un ranking o un listado de influencers a

Tabla 1. Perfil de la muestra

\begin{tabular}{|l|c|}
\hline Período temporal de la muestra resultante & 50 \\
\hline Vídeos analizados (análisis contenido) & 574 \\
\hline $\begin{array}{l}\text { Duración del visionado en minutos } \\
\text { (análisis de contenido) }\end{array}$ & 500 \\
\hline Vídeos previos al cribado (1:10) & 5.740 \\
\hline Duración del visionado en minutos (1:10) & YouTube \\
\hline Plataforma de intercambio de vídeo & \\
\hline
\end{tabular}


partir de fuentes como Social Blade. Ni siquiera un filtrado manual en Social Blade resultó útil. A partir de aquí se optó por un cribado directo en YouTube mediante palabras clave: apuestas en directo, apuesta segura, apuesta deportiva segura, jugadores apuesta, apostar y ganar dinero. El filtrado ha supuesto una ratio de selección aproximada de 1:10, resultando una muestra de conveniencia final de 50 vídeos y 574 minutos de visionado. El lapso de tiempo resultante ha sido del 23 de noviembre de 2016 al 6 de mayo de 2020. La tabla 1 recoge los datos de la muestra.

El análisis incluye 14 variables y un total de 52 categorías. Entre otras se analiza el target (menores y jóvenes), las temáticas, las edades de los protagonistas, o se manejan indicadores como los estilos de vida o la forma de hablar de los youtubers. La tabla 2 recoge la ficha de análisis empleada. Cubre los objetivos OS1, OS2 y OS4.

Tabla 2. Variables y categorías de análisis

\begin{tabular}{|c|c|}
\hline Variable & Categorías \\
\hline Target & Menores / Jóvenes / Adultos \\
\hline Protagonista o co-protagonista & Masculino / Femenino \\
\hline Rango de edad & Menor / Joven / Adulto \\
\hline Perfil & $\begin{array}{l}\text { Profesional (Persona / Canal) } \\
\text { Esporádico (Persona / Canal) }\end{array}$ \\
\hline $\begin{array}{l}\text { Categoría del canal (clasificación } \\
\text { YouTube) }\end{array}$ & $\begin{array}{l}\text { Cine y animación } \\
\text { Deportes } \\
\text { Entretenimiento } \\
\text { Formación } \\
\text { Gente y blogs } \\
\text { Videojuegos } \\
\text { Otras }\end{array}$ \\
\hline Juegos y actividades del juego & $\begin{array}{l}\text { Tipsters (pronosticadores) } \\
\text { Cajas sorpresa } \\
\quad \text { Vinculadas a videojuegos } \\
\quad \text { No vinculadas a videojuegos } \\
\text { Vídeos tutoriales } \\
\text { Formación } \\
\text { Casino } \\
\text { Poker } \\
\text { Ruleta } \\
\text { Tragaperras } \\
\text { Reportajes }\end{array}$ \\
\hline $\begin{array}{l}\text { Formato audiovisual } \\
\text { (modalidad del producto) }\end{array}$ & $\begin{array}{l}\text { Directo } \\
\text { Falso directo } \\
\text { Consejos }\end{array}$ \\
\hline Formatos publicitarios & $\begin{array}{l}\text { Publicidad convencional } \\
\text { Publicidad verbalizada } \\
\text { Promoción sobreimpresionada } \\
\text { Enlaces al operador del juego o al youtuber }\end{array}$ \\
\hline $\begin{array}{l}\text { Presencia de marcas relacionadas con } \\
\text { el juego }\end{array}$ & $\begin{array}{l}\text { Presencia de marca } \\
\text { Relacionada con el juego } \\
\text { Marcas gancho para promover el vídeo } \\
\text { Ausencia de marca }\end{array}$ \\
\hline $\begin{array}{l}\text { Identificación } \\
\text { (art. } 7 \text { RDCCAJ y art. } 3 \text { CCCAJ) }\end{array}$ & Las comunicaciones comerciales deben ser claramente identificables y reconocibles como tales \\
\hline $\begin{array}{l}\text { Veracidad } \\
\text { (art. } 8 \text { RDCCAJ y art. } 4 \text { CCCAJ) }\end{array}$ & $\begin{array}{l}\text { No incluirá información, aun siendo cierta, que pueda inducir a error o confusión a los destinatarios } \\
\text { No omitirá o silenciará hechos relevantes si ello induce a error a los destinatarios }\end{array}$ \\
\hline $\begin{array}{l}\text { Responsabilidad social } \\
\text { (art. } 9 \text { RDCCAJ y art. } 4 \text { CCCCAJ) }\end{array}$ & $\begin{array}{l}\text { El juego se asocia con aspectos positivos sin referirse a los daños que pueda ocasionar } \\
\text { Se desvaloriza el esfuerzo } \\
\text { Se representa gráficamente el dinero }\end{array}$ \\
\hline Juego informado (art. 10) & $\begin{array}{l}\text { Patrones de juego como prácticas estimulantes o atractivas sin riesgo } \\
\text { El juego vinculado con el éxito profesional } \\
\text { La repetición aumenta la posibilidad de ganar } \\
\text { La actividad del juego se asimila a una actividad económica o inversión } \\
\text { Aviso de texto "juega con responsabilidad", "si juegas, sé responsable" o similar }\end{array}$ \\
\hline Menores (art. 11) & $\begin{array}{l}\text { Explotar la confianza que los menores tienen con personajes famosos, padres, profesores... } \\
\text { Indicación de "menores no"," }+18 \text { " o similar }\end{array}$ \\
\hline
\end{tabular}

Por otra parte, se ha identificado mediante observación semiestructurada, la presencia de actividad promocional relacionada con la actividad del juego en 13 canales y plataformas (Betsfy, BlogaBet, Facebook, InBestment, Instagram, Spotify, Telegram, TikTok, Twitch, Twitter, Web, WhatsApp y YouTube) entre 20 tipsters. La observación se realizó entre el 25 de febrero de 2020 y el 31 de mayo de 2020. Con ello se contemplan los objetivo OS3 y OS4. 
Por último, se ha realizado un análisis tanto intrínseco como comparativo del marco normativo español sobre la promoción de actividades del juego, para su cotejo con los resultados obtenidos en OS1 y OS3. Para este análisis se transforman los textos normativos en variables (entre otras: veracidad, responsabilidad social, juego informado, advertencias al menor). Con ello se cubre el objetivo OS5. La normativa completa empleada queda recogida en la tabla 3, si bien el detalle metodológico y los resultados completos exceden al trabajo actual.

Tabla 3. Normativa empleada

\begin{tabular}{|c|c|}
\hline Normativa & Siglas empleadas \\
\hline \multicolumn{2}{|l|}{ Normativa nacional sobre actividad del juego } \\
\hline $\begin{array}{l}\text { Real decreto-ley 11/2020, de } 31 \text { de marzo, por el que se adoptan medidas urgentes complementarias en el ámbito social y } \\
\text { económico para hacer frente al Covid-19 (España, 2020c). }\end{array}$ & RDL 11/2020-COVID-19 \\
\hline Real decreto 958/220, de 3 de noviembre, de comunicaciones comerciales en la actividad del juego (España, 2020a). & PRDCCAJ \\
\hline Código de conducta sobre comunicaciones comerciales de las actividades de juego de 2019 (Autocontrol, 2019). & CCCCAJ \\
\hline Ley 13/2011, de 27 de mayo, de regulación del juego (España, 2011). & LRJ \\
\hline $\begin{array}{l}\text { Real decreto 495/2020, de } 28 \text { de abril, por el que se desarrolla la estructura orgánica básica del Ministerio de Consumo y se } \\
\text { modifica el real decreto 139/2020, de } 28 \text { de enero, por el que se establece la estructura orgánica básica de los departamen- } \\
\text { tos ministeriales (España, 2020a). }\end{array}$ & RD 495/2020 \\
\hline $\begin{array}{l}\text { Real decreto 139/2020, de } 28 \text { de enero, por el que se establece la estructura orgánica básica de los departamentos ministe- } \\
\text { riales (España, 2020d). }\end{array}$ & RD 139/2020 \\
\hline \multicolumn{2}{|l|}{ Normativa nacional sobre comunicación } \\
\hline Ley 7/2010, de 31 de marzo, general de la comunicación audiovisual (España, 2010). & LGCA \\
\hline $\begin{array}{l}\text { Ley 34/1988, de } 11 \text { de noviembre, general de publicidad [Texto consolidado a } 28 \text { de marzo de 2014] (España, 1988, } \\
\text { actualizado 2021). }\end{array}$ & LGP \\
\hline \multicolumn{2}{|l|}{ Normativa europea sobre actividad de juego } \\
\hline Directiva de comunicación audiovisual (UE) 2018/1808 del Parlamento Europeo y del Consejo (Unión Europea, 2018). & Directiva 2018/1808 \\
\hline Directiva de Comunicación Audiovisual 2010/13/UE del Parlamento Europeo y del Consejo (Unión Europea, 2010). & Directiva 2010/13/UE \\
\hline
\end{tabular}

\section{Resultados y discusión}

\subsection{Perfil de los youtubers promotores de juegos de azar (OS2)}

Los resultados muestran que los youtubers que promueven comunicaciones comerciales sobre juego son mayoritariamente hombres (85\%), con cifras de audiencia muy variables según subperfiles o temáticas, pudiendo ser desde microinfluencers (Carlos López, 65.500 suscriptores; LePicks, 54.500 suscriptores o Apuestas Gayá, 6.770 suscriptores) a canales con millones de seguidores (Agustín51, 4,32 millones de suscriptores; PokeR988TV, 1,97 millones de suscriptores). Su edad está relacionada con el tipo de producto que promocionan. Así, las cajas-sorpresa no vinculadas a videojuegos estarían promovidas por youtubers más jóvenes y de perfil esporádico.

Se han identificado dos grandes tipos de youtubers y canales: profesionales y esporádicos.

- "canales profesionales" son los dedicados exclusiva o fundamentalmente a las actividades de juegos (como tipsters o canales de operadores de juego);

- "youtubers esporádicos" son los que se dedican a otros temas pero que, ocasionalmente, incluyen algunos vídeos sobre juego (Agustín51).

No se han identificado canales de empresas ajenas al juego que puntualmente publiquen vídeos sobre actividad de juego. A partir de la muestra con la que se ha trabajado (y teniendo presente que procede de un cribado) el $60 \%$ de los vídeos analizados son canales profesionales y el $40 \%$ youtubers esporádicos.

\subsection{Categoría de canales y target de los vídeos (OS2)}

Los canales que tratan sobre juego se distribuyen en categorías muy diversas. El estudio identificó hasta 5 (Cine y animación, Deportes, Entretenimiento, Formación, Gente y blogs y Videojuegos). El 76\% de los vídeos se concentra en las categorías Entretenimiento y Videojuegos. En los canales de “Entretenimiento" (32\%) el perfil es el de un youtuber profesional (es decir, que habitual o exclusivamente trata sobre contenidos de actividades de juego), mientras que en la categoría "Videojuegos" (44\%) los youtubers son tanto profesionales como esporádicos (que ocasionalmente tratan sobre actividades de juego). El gráfico 1 resume las categorías detectadas.

En la muestra seleccionada se ha observado que los contenidos se dirigen principalmente a jóvenes o menores. Para ello se han tomado como criterios la apariencia del influencer, su actitud, el lenguaje o las situaciones en las que aparecen. Así los contenidos se graban en lugares reconocibles por los jóvenes como gimnasios, la habitación de sus casas o con sus amigos como actividades que se hacen en grupo como parte de la aceptación social de los jóvenes. También destaca la presencia de infografías y dibujos o

Los youtubers que promueven comunicaciones comerciales sobre juego son mayoritariamente hombres (85\%) 
la utilización de sobreimpresiones de dibujos, animales y colores que son más propios de un público infantil que juvenil. Los formatos de los vídeos de esta temática, como veremos más adelante, son directos, consejos o falsos directos con el objeto de tener una mayor vinculación con el público joven. De la muestra seleccionada hemos detectado que un $50 \%$ de los contenidos están dirigidos a jóvenes y menores, un $28 \%$ a los adultos y un $22 \%$ a ambos públicos.

\subsection{Contenidos de los vídeos y su vinculación con los jóvenes y me- nores (OS4)}

Se han observado cinco tipos de contenidos recurrentes sobre actividades de juego de azar en los vídeos:

- tipsters: apuestas deportivas

- loot box: cajas sorpresa

- casino/poker/ruleta/tragaperras

- formación y tutoriales: el youtuber explica reglas del juego, trucos para jugar o términos propios del mundo de las apuestas deportivas

- reportajes: se comentan jugadas de profesionales.

Las cajas sorpresa y los tipsters son los más próximos a los menores y jóvenes respectivamente.

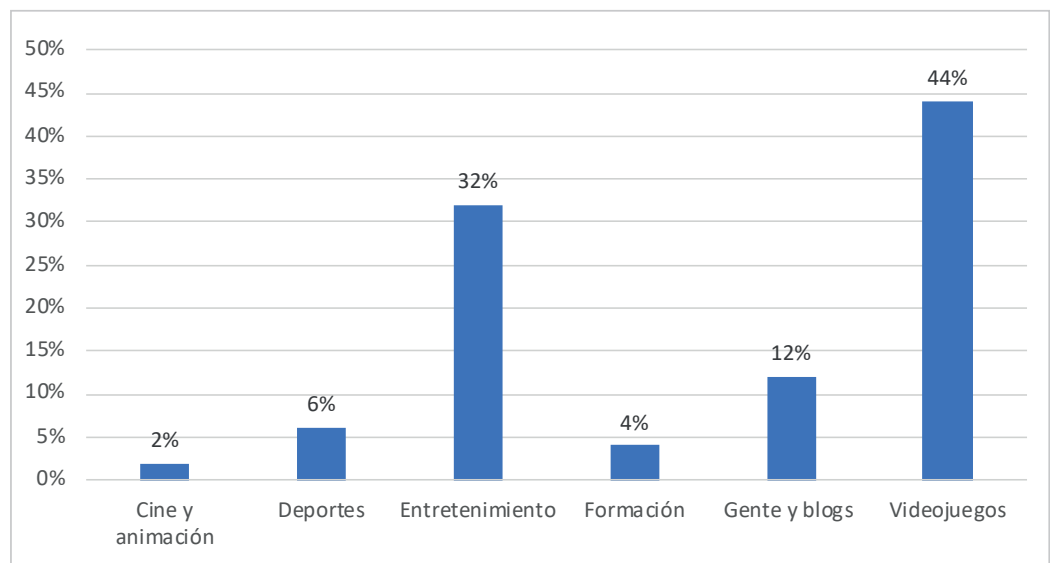

Gráfico 1. Categorías de los canales que tratan sobre actividades del juego (categorías YouTube)

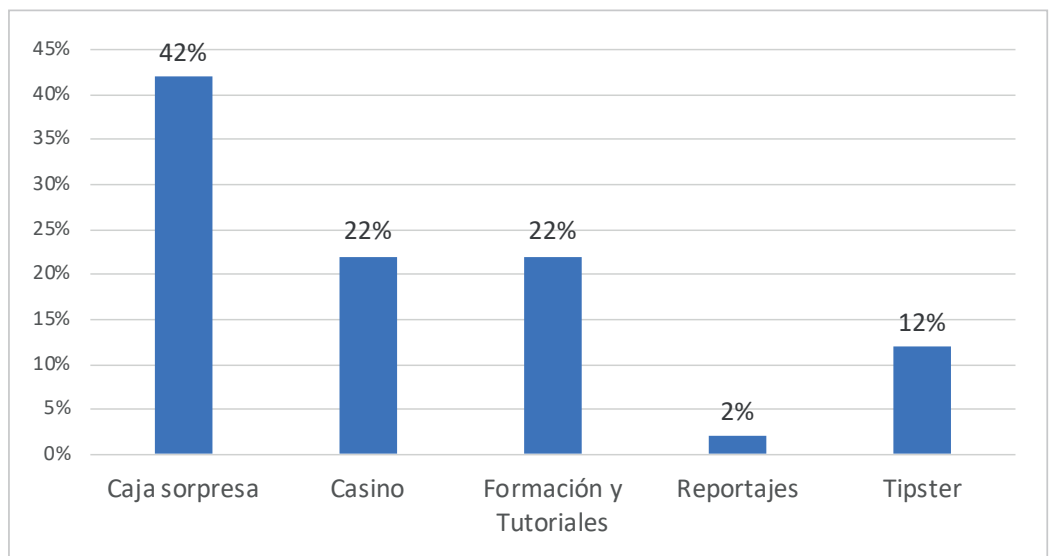

Gráfico 2. Tipos de contenidos sobre actividades de juego en YouTube

En el análisis se ha comprobado que las apuestas deportivas son protagonizadas por tipsters o pronosticadores profesionales. Se caracterizan por suscripciones y visualizaciones muy limitadas (desde los 3.930 suscriptores de Jobet - The Best Bet, los 6.770 seguidores de Apuestas Gayá o los 65.100 de Carlos López). Los contenidos de estas apuestas deportivas sirven para la promoción directa de servicios, como suscripciones premium del tipsters, cursos de formación del tipsters o promociones de operadores del juego (códigos-regalo por participar en el operador de apuestas).

Como puede apreciarse en el gráfico 2 los contenidos sobre cajas sorpresa y tipsters acumulan más del 50\% de los vídeos analizados.

En cuanto a las loot boxes, en este estudio se han identificado cajas de dos tipos: unas vinculadas a videojuegos y otras sin relación con ellos.

- Entre las primeras destaca CS:GO - CounterStrike: Global Offensive. Aquí la finalidad es obtener objetos virtuales para el videojuego (denominados skins).

- Las cajas sorpresa no vinculadas a videojuegos son las más peligrosas: premios en productos, desde un llavero a un potente ordenador o teléfono móvil de última generación.

En todos los casos el usuario paga un precio por abrirlas y de forma aleatoria puede ganar diferentes regalos físicos o intangibles (armas para videojuegos). Igualmente se ha comprobado que se pueden realizar transacciones: quedarse con los objetos, venderlos para abrir otras cajas, o incluso cobrarlos en metálico vendiéndolos a través de plataformas paralelas. Por ejemplo Steam (una plataforma de distribución digital de videojuegos) permite incorporar skins (personalizaciones) a través de otras plataformas como OpenSkin (bloqueada desde 2018), BitSkin, CS.Money, HellCase o Skin Club.

\subsection{Formatos publicitarios (OS1)}

A partir de los diferentes formatos que pueden encontrarse en la diversa bibliografía (IAB, 2019a; Martínez-Pastor et al., 2020; Ramos-Serrano; Herrero-Diz, 2016, CCDDCC-FC, 2015, Wu, 2016; IAB, 2018; Martínez-Pastor et al., 2017; Federal Trade Commission, 2015) el estudio ha identificado que dentro de los vídeos que los usuarios cuelgan en YouTube se dan a su vez las siguientes moda-
El usuario paga un precio por abrir las loot boxes (cajas sopresa) y de forma aleatoria puede ganar diferentes regalos físicos o intangibles (por ej., "armas" para videojuegos) 
lidades o formatos de posibles comunicaciones comercial a partir de indicios publicitarios observados:

- publicidad convencional (como un spot de televisión insertados en el propio vídeo del youtuber),

- publicidad verbalizada durante el transcurso del vídeo,

- promoción sobreimpresionada y

- enlaces al operador de juego o a servicios del propio youtuber.

La presencia de estos formatos parte, a su vez, de ciertos indicios publicitarios entre los que se encuentra la presencia de marcas. Solo en el $22 \%$ de los vídeos analizados no aparecen marcas (gráfico 3).

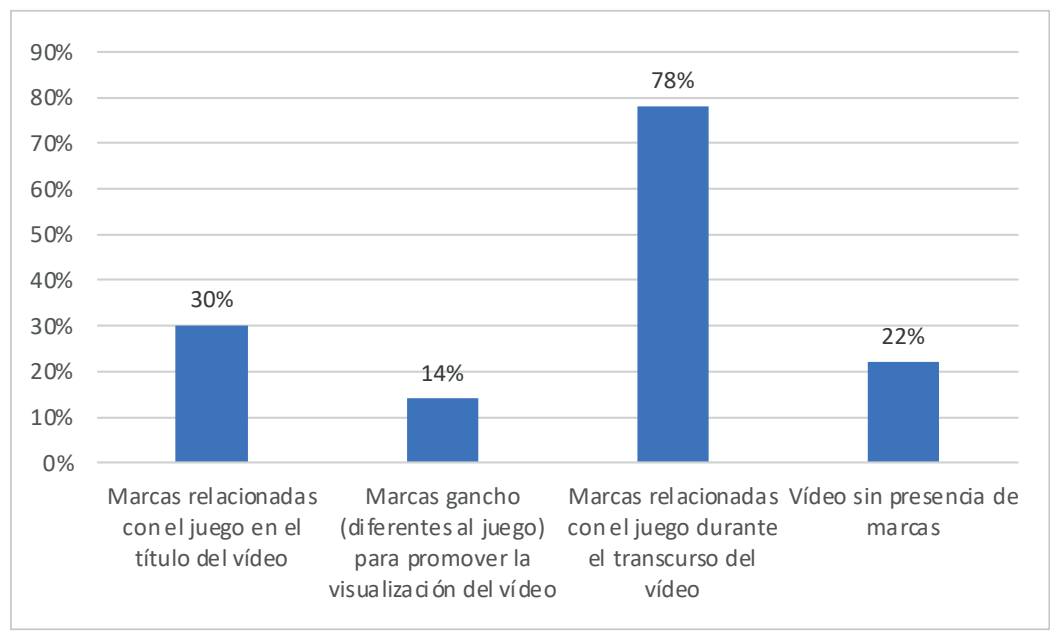

Gráfico 3. Presencia de marcas en los vídeos de YouTube (indicios publicitarios)

\subsection{Nuevos formatos, contenidos, canales y normativa en relación con los menores (OS3, OS4 y OS6)}

Una de las aportaciones principales del estudio ha sido comprobar que no sólo la promoción del juego de azar en internet se produce por medio de formatos publicitarios diferentes a los convencionales, sino que también se realiza a través de canales muy diversos. Así, la promoción del juego, además de estar presente en YouTube (objeto principal de estudio en esta investigación) y en webs o apps especializadas (como InBestment, Betsfy, BlogaBet) lo está en entornos tan variopintos como Facebook, Instagram, Spotify, Telegram, TikTok, Twitch, Twitter o WhatsApp, entornos todos ellos muy cercanos a jóvenes y menores.

Si nos centramos en contenidos determinados, el caso de las cajas sorpresa despierta discrepancias. La LRJ (a la que alude el RDCCAJ en su ámbito de aplicación a través del art. 3) recoge actividades de juego de forma genérica (loterías, apuestas, rifas y concursos; art. 3 LRJ) y concreta términos (juego; loterías, apuestas, rifas y concursos). Algunos de ellos se detallan de forma pormenorizada. Así, en cuanto a las apuestas se diferencian:

- tipos: apuesta deportiva, apuesta hípica y otras apuestas;

- modalidades: apuesta mutua, apuesta de contrapartida y apuesta cruzada.

Ciertos juegos se mencionan de forma explícita, como el poker y la ruleta, citados como juegos de la categoría "Otros juegos". En este sentido en el estudio se han identificado juegos hasta ahora poco convencionales (dado que los cambios tecnológicos han permitido que determinados juegos den un salto cuantitativo en cuanto a su dimensión económica) pero que, dada su relación con un potencial público menor, el RDCCAJ debería explicitar. Es el caso de las cajas sorpresa, el Crash o juegos clásicos adaptados al entorno de las apuestas digitales (por ej., Monopoly).

Por otro lado en el estudio se ha observado que, si bien ciertos mensajes de los vídeos podrían considerarse como un contenido anecdótico (ganar en una apuesta podría ser algo excepcional que el youtuber muestra a su audiencia en un caso concreto), visto en el conjunto de varios vídeos (donde se repite dicho éxito fácil con una misma marca, y el youtuber expresa siempre grandes emociones) supone una publicidad que contravendría varios principios que plantea el PRDCCAJ, como el de Identificación, Veracidad o Responsabilidad Social.

El estudio también ha comprobado que existe una intencionalidad manifiesta de bordear la regulación. Sucede así cuando determinados indicios publicitarios colisionan con las declaraciones explícitas de los youtubers, que afirman no estar relacionados con las marcas. Así hay youtubers que afirman que en sus vídeos el contenido no es patrocinado; sin embargo, hay indicios que pudieran hacer pensar que se trata de una comunicación comercial. En concreto se encontraron:

- Presencia de código promocional del operador de juego, personalizado con el nombre del canal de YouTube (código promocional "theni", canal del youtuber "soyTHENI");

- Presencia del producto a lo largo de todo el vídeo (9 minutos);

- Presencia de la marca en el título del vídeo;

- Insistencia en que el usuario acceda a la marca pese a las supuestas restricciones de YouTube mediante la verbalización y visualización de la dirección web del posible anunciante y la inclusión de su url en el título del vídeo;

- Edición del vídeo: zoom para ampliar el logotipo de la marca.
Existe una intencionalidad manifiesta de bordear la regulación. Sucede así cuando determinados indicios publicitarios colisionan con las declaraciones explícitas de los youtubers, que afirman no estar relacionados con las marcas 


\section{Conclusiones}

En YouTube se han identificado posibles comunicaciones comerciales sobre actividades de juego vinculadas con un público potencialmente joven o incluso menores, bien porque los influencers que participan aparentan una edad entorno a los 18-20 años (y por tanto con muchas posibilidades de empatizar con un menor de edad), bien por sus actitudes o por el tipo de producto que promocionan (cajas sorpresa).

Los influencers se deben considerar explícitamente como personajes susceptibles de utilizar la confianza de los menores. El RDCCAJ considera contrario al principio de protección de menores que las comunicaciones comerciales puedan explotar

“la especial relación de confianza que los menores depositan en sus padres, profesores, u otras personas" (art. 11).

Este artículo debería concretar más, por ejemplo:

“...sus padres, profesores, personajes famosos para ellos (incluidos los influencers de medios online) u otras personas",

lo cual acercaría la ley a la realidad actual y evitaría que una expresión tan amplia resulte en una regulación vacía de contenido.

Las actividades del juego son muy diversas y exigen una cierta especialización o nivel de conocimiento, por lo que la formación a través de tutoriales supone una parte considerable de los contenidos de los vídeos (22\%). Esta especialización es más necesaria en el caso de las apuestas deportivas, donde los tutoriales y los pronósticos gratuitos son la excusa para ofrecer los servicios premium (de pago) de los tipsters o pronosticadores profesionales. Así pues, los propios contenidos (cursos gratuitos, pronósticos gratuitos, consejos o trucos) se convierten en el puente hacia los servicios del youtuber. En realidad se están difundiendo contenidos comerciales en un doble sentido:

- promoción de la marca del juego de azar (como cajas sorpresa);

- promoción de la marca del youtuber.

Estos juegos deberían haberse regulado por el RDCCAJ. Es el caso de las cajas sorpresa, el Crash o juegos clásicos adaptados al entorno de las apuestas digitales (Monopoly). El Ministerio de Sanidad, Consumo y Bienestar Social estuvo planteando el modo de regular las cajas de recompensa (Fernández, 2020), pese a que podrían estar ya contempladas en la Ley.

Los propios contenidos de los vídeos podrían constituir por sí mismos comunicaciones comerciales (Tipsters; Loot box; casino, poker, ruleta, tragaperras; formación y tutoriales y reportajes). En estos contenidos, a su vez, se incluyen formatos publicitarios fusionándose en un único producto, de manera que podríamos indicar que es un nuevo formato en sí mismo el contenido de entretenimiento y los formatos que aparecen en los vídeos.

En este caso sería una manera de autopromoción del propio youtuber. El RDCCAJ tiene la oportunidad de incorporar explícitamente la autopromoción como un tipo de comunicación comercial cuando la misma se haga en canales con contenidos relacionados con la actividad de juego y cuando la realice un youtuber con el objeto de reforzar su imagen de marca. La autopromoción es la modalidad de comunicación comercial más habitual entre los youtubers relacionados con la actividad del juego. Estas autopromociones lo son sobre contenidos que pueden fomentar actitudes negativas hacia el consumidor o que están orientadas a menores de edad. Se han identificado comunicaciones comerciales en formatos diferentes a los tradicionales que la actual redacción del RDCCAJ deja fuera. Si estas comunicaciones comerciales (consideradas así a partir de indicios publicitarios) no se consideraran como tales, supondría que el $94 \%$ de la publicidad que se realiza en YouTube sobre actividades del juego quedaría al margen de esta legislación.

Se hace necesario aplicar criterios de identificación de publicidad más rigurosos, en especial para proteger a los menores. En el estudio se observa que las escasas ocasiones en las que la publicidad se identifica (6\%), en la mayoría de los casos no queda señalada claramente como contenido comercial. Los usuarios tienen el derecho de conocer que los vídeos no son contenidos meramente de entretenimiento, formativos o educativos, sino que pueden tener una clara finalidad comercial. Así lo indica la Ley general de comunicación audiovisual (LGCA) para los medios convencionales:

"aquellas formas de publicidad distintas de los anuncios televisivos que, por las características de su emisión, podrían confundir al espectador sobre su carácter publicitario"

En los publireportajes, telepromociones, etc., deberá superponerse, permanentemente y de forma claramente legible, una transparencia con la indicación "publicidad" o terminar a toda pantalla y durante 2 segundos con un aviso sobre su carácter publicitario. En este sentido el RDCCAJ sólo indica que:

"las comunicaciones comerciales deben ser claramente identificables y reconocibles como tales" (art. 7) 
A la vista de lo observado en este estudio, la redacción del texto resulta excesivamente imprecisa en un aspecto (el del Principio de identificación de las comunicaciones comerciales) que es necesario definir explícitamente como lo hace con otros conceptos como "redes publicitarias". El propio CCCCAJ sí es mucho más preciso. Sin embargo, dicho código de conducta tampoco contempla la total realidad de la publicidad online, pues maneja un concepto tradicional. Así, la referencia a incluir un mensaje estandarizado a toda pantalla durante 2 segundos al final de la publicidad resulta útil en un spot convencional de 10 ó 30 segundos, pero resultaría inadecuado para los nuevos formatos publicitarios de internet, donde un vídeo completo de un youtuber puede ser en sí mismo una comunicación comercial. Entendemos que esta normativa tenía una oportunidad para proteger más adecuadamente al menor y sin embargo entendemos que le ha quedado camino por recorrer.

Asimismo, sería conveniente que la Unión Europea llevara a cabo alguna normativa ad hoc sobre los juegos de azar, menores y publicidad aunando las legislaciones desplegadas en cada país miembro y las actividades permitidas en el contexto europeo. La mayoría de los países de la UE permiten que algunos juegos de azar se ofrezcan en internet, algunos países permiten todos los juegos, mientras que otros sólo permiten ciertos tipos como las apuestas, el poker o los juegos de casino. En algunos países permiten monopolios que proporcionan servicios de juegos de azar online, mientras que la mayor parte de los países de la Unión Europea ha establecido sistemas de licencias que permiten ofrecer servicios en el mercado a más de un operador.

\section{Referencias}

Abarbanel, Brett; Gainsbury, Sally; King, Daniel; Hing, Nerile; Delfabbro, Paul (2017). "Gambling games on social platforms: How do advertisements for social casino games target young adults?". Policy \& internet, v. 9, n. 2, pp. $184-209$. https://doi.org/10.1002/poi3.135

Anderson, Monica; Jiang, Jingjing (2018). Teens, social media \& technology 2018. Pew Research Center, 31 May. https://pewrsr.ch/2MAb3P5

Autocontrol (2019). Código de conducta sobre comunicaciones comerciales de las actividades de juego. https://cutt.ly/thOeyiN

Buil, Pilar; Solé-Moratilla, María-José; García-Ruiz, Pablo (2015). "La regulación publicitaria de los juegos de azar online en España. Una reflexión sobre la protección del menor". Adicciones, v. 27, n. 3, pp. 198-204.

https://doi.org/10.20882/adicciones. 706

Busby, Mattha (2017). "Revealed: How gambling industry targets poor people and ex-gamblers". The guardian, 31 August.

https://bit.ly/3eXQUi9

Calado, Filipa; Alexandre, Joana; Griffiths, Mark D. (2017). “Prevalence of adolescent problem gambling: A systematic review of recent research". Journal of gambling studies, v. 33, n. 2, pp. 397-424.

https://doi.org/10.1007/s10899-016-9627-5

Campbell, Colin; Marks, Lawrence J. (2015). “Good native advertising isn't a secret”. Business horizons, v. 58, n. 6, pp. 599-606.

https://doi.org/10.1016/j.bushor.2015.06.003

Carbonell-Vayá, Enrique; Montiel-Juan, Irene (2013). El juego de azar online en los nativos digitales. Valencia: Tirant lo Blanch. ISBN: 9788415731245

Caselles-Cámara, Pablo; Cabrera-Perona, Víctor; Lloret-Irles, Daniel (2018). “Prevalencia del juego de apuestas en adolescentes. Un análisis de los factores asociados". Health and addictions, v. 18, n. 2, pp. 165-173.

https://doi.org/10.21134/haaj.v18i2.392

Cases-Méndez, José-Ignacio; Gómez-Yáñez, José-Antonio; Gusano-Serrano, Germán; Lalanda-Fernández, Carlos (2018). Percepción social sobre el juego de azar en España 2018, IX. Madrid: Universidad Carlos III de Madrid: Instituto de Política y Gobernanza.

https://bit.ly/2XG2Hfl

Cauberghe, Veroline; Hudders, Liselot; Adams, Britt; Daems, Kristien; De-Jans, Steffi; De-Pauw, Pieter; Lissens, Silke; Verdoodt, Valerie; Zarouali, Brahim; Bouwens, Joke; De-Pelsmacker, Patrick; Lievens, Eva; Moons, Ingrid; Poels, Karolien; Ponnet, Koen; Schellens, Tammy; Valcke, Martin; Valcke, Peggy; Walrave, Michel; (2016). Minors' advertising literacy in relation to new advertising formats-Identification and assessment of the risks. AdLit SBO.

https://bit.ly/2VaoeOi 
CCDDCC-FC (2015). Request for investigation into Google's unfair and deceptive practices in connection with its YouTube Kids app. Washington, USA: Counsel for Center for Digital Democracy and Campaign for a Commercial-Free Childhood. https://www.law.georgetown.edu/wp-content/uploads/2018/12/12-19-Google-Play-Store-Complaint-With-Exhibits.pdf

Chóliz, Mariano; Lamas, Juan (2017). “iHagan juego, menores! Frecuencia de juego en menores de edad y su relación con indicadores de adicción al juego". Revista española de drogodependencias, v. 42, n. 1, pp. 34-47.

https://bit.ly/38MqY8H

Cid, Guillermo (2019). “Decenas de famosos 'youtubers' españoles anuncian apuestas y 'cajas sorpresa' ilegales". El confidencial, 18 noviembre.

https://bit.ly/3eY8BOW

Cosenza, Marina; Nigro, Giovanna (2015). "Wagering the future: Cognitive distortions, impulsivity, delay discounting, and time perspective in adolescent gambling". Journal of adolescence, v. 45, pp. 56-66.

https://doi.org/10.1016/j.adolescence.2015.08.015

Craig, David; Cunningham, Stuart (2017). "Toy unboxing: Living in a(n unregulated) material world". Media international Australia, v. 163, n. 1, pp. 77-86.

https://doi.org/10.1177/1329878X17693700

Derevensky, Jeffry; Sklar, Alissa; Gupta, Rina; Messerlian, Carmen (2010). "An empirical study examining the impact of gambling advertisements on adolescent gambling attitudes and behaviors". International journal of mental health and addiction, v. 8, n. 1, pp. 21-34.

https://doi.org/10.1007/s11469-009-9211-7

Dirección General de Ordenación del Juego (2016). Estudio sobre prevalencia, comportamiento y características de los usuarios de juegos de azar en España. Ministerio de Consumo, Dirección General de Ordenación del Juego.

https://www.ordenacionjuego.es/es/estudio-prevalencia

Dirección General de Ordenación del Juego (2018a). Mercado del juego online estatal. Ministerio de Consumo, Dirección General de Ordenación del Juego.

https://www.ordenacionjuego.es/es/noticia-mercado-juego-online-estatal-2018

Dirección General de Ordenación del Juego (2018b). Análisis del perfil del jugador online. Ministerio de Consumo, Dirección General de Ordenación del Juego.

https://www.ordenacionjuego.es/es/noticia-informe-jugador-online-2018

Dirección General de Ordenación del Juego (2019). Memoria de actividad 2019. Ministerio de Consumo, Dirección General de Ordenación del Juego.

https://www.ordenacionjuego.es/es/memorias-informe-anual

España (1988, actualizado 2021). “Ley 34/1988, de 11 de noviembre, general de publicidad”. BOE, n. 274,15 noviembre. https://www.boe.es/buscar/act.php?id=BOE-A-1988-26156

España (2010) “Ley 7/2010, de 31 de marzo, General de la comunicación audiovisual”. BOE, n. 79, 1 abril. https://www.boe.es/buscar/act.php?id=BOE-A-2010-5292

España (2011). “Ley 13/2011, de 27 de mayo, de regulación del juego”. BOE, n. 127, 28 mayo.

https://www.boe.es/buscar/act.php?id=BOE-A-2011-9280

España (2020a). "Real decreto 958/220, de 3 de noviembre, de Comunicaciones comerciales en la actividad del juego". $B O E$, n. 291, 4 noviembre.

https://www.boe.es/buscar/doc.php?id=BOE-A-2020-13495

España (2020b). “Real decreto 495/2020, de 28 de abril, por el que se desarrolla la estructura orgánica básica del Ministerio de Consumo y se modifica el real decreto 139/2020, de 28 de enero, por el que se establece la estructura orgánica básica de los departamentos ministeriales". BOE, n. 121, 1 mayo.

https://www.boe.es/eli/es/rd/2020/04/28/495

España (2020c). “Real decreto-ley 11/2020, de 31 de marzo, por el que se adoptan medidas urgentes complementarias en el ámbito social y económico para hacer frente al Covid-19". BOE, n. 91, 1 abril.

https://www.boe.es/buscar/act.php?id=BOE-A-2020-4208

España (2020d). "Real decreto 139/2020, de 28 de enero, por el que se establece la estructura orgánica básica de los departamentos ministeriales". BOE, n. 25, 29 enero.

https://www.boe.es/buscar/act.php?id=BOE-A-2020-1246

European Gaming and Betting Association (2020).

https://www.egba.eu/about-us 
Federal Trade Commission (2015). The FTC's endorsement guide. What people are asking. https://bit.ly/1FRMynQ

Fernández, Borja (2020). “¿Qué son las «loot boxes` que quiere regular Garzón y por qué pueden incitar a la ludopatía?”. Público, 28 febrero.

https://cutt.ly/hz9HDOU

Gambling Commission (2017). Young people and gambling 2017: A research study among 11-16 year olds in Great Britain. https://bit.ly/2Ac9hkL

García-Rodríguez, Carlos (2017). El marco jurídico de los juegos de azar y la incidencia de las nuevas tecnologías. Tesis doctoral. Universidad Complutense de Madrid.

https://eprints.ucm.es/40959

García-Ruiz, Pablo; Buil, Pilar; Solé-Moratilla, María-José (2016). “Consumo de riesgo: menores y juegos de azar online. El problema del 'juego responsable'”. Política y sociedad, v. 53, n. 2, pp. 551-575.

https://doi.org/10.5209/rev_POSO.2016.v53.n2.47921

Gardner, Jacob; Lehnert, Kevin (2016). "What's new about new media? How multi-channel networks work with content creators". Business horizons, v. 59, n. 3, pp. 293-302.

https://doi.org/10.1016/j.bushor.2016.01.009

González-Roz, Alba; Fernández-Hermida, José-Ramón; Weidberg, Sara; Martínez-Loredo, Víctor; Secades-Villa, Roberto (2017). "Prevalence of problem gambling among adolescents: a comparison across modes of access, gambling activities, and levels of severity". Journal of gambling studies, v. 33, n. 2, pp. 371-382.

https://doi.org/10.1007/s10899-016-9652-4

Griffiths, Mark D. (2018). “Is the buying of loot boxes in video games a form of gambling or gaming?”. Gaming law review and economics, v. 22, n. 1, pp. 52-54.

https://doi.org/10.1089/g/r2.2018.2216

Hernández-Ruiz, Alejandra (2020). "La protección al consumidor en las webs de juego online de los operadores con licencia en España”. Adicciones, v. 32, n. 3, pp. 216-223.

https://doi.org/10.20882/adicciones.1262

Hidalgo-Cerezo, Alberto (2019). "Loot boxes: juegos de azar encubiertos al alcance de menores". Revista jurídica de Castilla y León, v. 47, pp. 25-58.

https://bit.ly/30gZ4yc

Holloway, Donell; Green, Lelia; Livingstone, Sonia (2013). Zero to eight. Young children and their internet use. London: EU kids online; LSE-The London School of Economics and Political Science.

http://eprints.Ise.ac.uk/52630/1/Zero_to_eight.pdf

Hörnle, Julia; Littler, Alan; Tyson, Gareth; Padumadasa, Eranjan; Schmidt-Kessen, Maria-José; Ibosiola, Damilola-Isaac (2018). Evaluation of regulatory tools for enforcing online gambling rules and channelling demand towards controlled offers. European Commission.

http://bit.ly/3vxbyP8

Hudders, Liselot; Cauberghe, Veroline; Panic, Katerina; De-Vos, Wendy (2016). “Children's advertising literacy for new advertising formats: The mediating impact of advertising literacy on the (un) intended effects of advergames and advertising funded programs". Advances in advertising research, v. 6, pp. 241-252. Wiesbaden: Springer Gabler. ISBN: 9783 658105587

https://doi.org/10.1007/978-3-658-10558-7_19

IAB (2018). Estudio anual de redes sociales 2018. IAB Spain.

https://iabspain.es/estudio/estudio-anual-de-redes-sociales-2018

IAB (2019a). Nuevos estándares de formatos publicitarios. IAB Spain.

https://iabspain.es/quienes-somos-iab-spain\#iab-spainformatos

IAB (2019b). Estudio anual de redes sociales 2019. IAB Spain.

https://iabspain.es/estudio/estudio-anual-de-redes-sociales-2019

IAB; PWC (2019). Estudio anual de inversión publicitaria en medios digitales 2019. IAB Spain.

https://iabspain.es/estudio/estudio-anual-de-inversion-publicitaria-en-medios-digitales-2019

Infoadex (2020). Estudio Infoadex de la inversión publicitaria en España 2020. Infoadex.

https://bit.ly/3AKFjih 
Kim, Hyoun S.; Wohl, Michael J. A.; Gupta, Rina; Derevensky, Jeffrey L. (2017). "Why do young adults gamble online? A qualitative study of motivations to transition from social casino games to online gambling". Asian journal of gambling issues and public health, v. 7, n. 6.

https://doi.org/10.1186/s40405-017-0025-4

Lamas, Juan (2017). "La prevención en el juego de azar". In: González-de-Audikana-de-la-Hera, Manuel (ed.). Repensando la prevención. Bilbao: Universidad de Deusto, pp. 123-134. ISBN: 9788416982394

Lock, S. (2020). “Gambling industry in Europe - Statistics \& facts". Statista, 3 December.

https://www.statista.com/topics/3660/gambling-industry-in-europe

Martínez-Pastor, Esther; Serrano-Maíllo, María-Isabel; Vizcaíno-Laorga, Ricardo; Nicolás-Ojeda, Miguel-Ángel (2017). Los niños ante la publicidad. Madrid: Ommpress.

https://bit.ly/2y8Ta30

Martínez-Pastor, Esther; Vizcaíno-Pérez, Ricardo; Nicolás-Ojeda, Miguel-Ángel; Serrano-Maíllo, María-Isabel; García-Maroto, Sofía (2020). Familias y niños: el negocio de los canales de los niños youtubers.

https://doi.org/10.13140/RG.2.2.18865.40806/1

Mcbride, Jessica; Derevensky, Jeffrey L. (2012). "Internet gambling and risk-taking among students: An exploratory study". Journal of behavioral addictions, v. 1, n. 2, pp. 50-58.

https://doi.org/10.1556/jba.1.2012.2.2

Miller, Carl; Krasodomski-Jones, Alex; Smith, Josh (2016). Gambling and social media. London: Demos.

https://www.begambleaware.org/media/1191/gambling-social-media-report-demos.pdf

Netherlands Gambling Authority (2018). Study into loot boxes. A treasure or a burden?

https://es.slideshare.net/OlivierOosterbaan/netherlands-gaming-authority-study-into-loot-boxes-a-treasure-or-a-burden

Newall, Philip W. S.; Moodie, Crawford; Reith, Gerda; Stead, Martine; Critchlow, Nathan; Morgan, Amber; Dobbie, Fiona (2019). "Gambling marketing from 2014 to 2018: A literature review". Current addiction reports, v. 6, pp. 49-56. https://doi.org/10.1007/s40429-019-00239-1

Newall, Philip W. S.; Thobhani, Ankush; Walasek, Lukasz; Meyer, Caroline (2019). "Live-odds gambling advertising and consumer protection". PLoS one.

https://doi.org/10.1371/journal.pone.0216876

Ofcom (2019). Children and parents: Media use and attitudes report 2018. Ofcom.

https://www.ofcom.org.uk/_data/assets/pdf_file/0024/134907/children-and-parents-media-use-and-attitudes-2018.pdf

Ofcom (2020). Children and parents: Media use and attitudes report 2019. Ofcom.

https://www.ofcom.org.uk/_data/assets/pdf_file/0023/190616/children-media-use-attitudes-2019-report.pdf

Olason, Daniel-Thor; Kristjansdottir, Elsa; Einarsdottir, Hafdis; Haraldsson, Haukur; Bjarnason, Geir; Derevensky, Jeffrey L. (2011). "Internet gambling and problem gambling among 13 to 18 year old adolescents in Iceland". International journal of mental health and addiction, v. 9, n. 3, pp. 257-263.

Orús, Abigail (2021). "Número medio de minutos que la población de 4 a 15 años pasaba en YouTube diariamente en Estados Unidos, Reino Unido y España entre mayo de 2019 y abril de 2020". Statista, 10 febrero.

https://es.statista.com/estadisticas/1124417/consumo-medio-diario-de-youtube-en-los-ninos-de-espana-ee-uu-yreino-unido

Pareja, Pol (2020). “El oscuro mundo de los 'tipsters', los pronosticadores que ejercen de gancho de las casas de apuestas". El confidencial, 21 enero.

http://bit.ly/2QdNil6

Parrado-González, Alberto; León-Jariego, José C. (2020). “Exposure to gambling advertising and adolescent gambling behaviour. Moderating effects of perceived family support". International gambling studies, v. 20, n. 2, pp. $214-230$.

https://doi.org/10.1080/14459795.2020.1712737

Pérez-Camarero, Santiago; Alcalá-Revilla, Bleric; Pérez-Cañellas, Gillermo (2018). Juventud y juegos de azar. Una visión general del juego en los jóvenes. Madrid: Injuve.

http://www.injuve.es/sites/default/files/adjuntos/2019/06/juventud_y_juegos_de_azar.pdf

PWC (2019). Kids digital media report 2019.

https://gertkoot.files.wordpress.com/2019/06/kids-digital-media-report-2019-.pdf

Raisamo, Susana; Halme, Jukkha; Murto, Antii; Lintonen, Tomi (2013). “Gambling-related harms among adolescents: A population-based study". Journal of gambling studies, v. 29, pp. 151-159.

https://doi.org/10.1007/s10899-012-9298-9 
Ramos-Serrano, Marina; Herrero-Diz, Paula (2016). "Unboxing and brand: Youtubers phenomenon through the case study of Evantubehd". Prisma social, v. especial 1, pp. 90120.

https://revistaprismasocial.es/article/view/1315/1379

Solé-Moratilla, María-José (2019). “¿Protege de manera efectiva la actual regulación de la publicidad de los juegos de azar online? Una reflexión sobre la protección de las personas vulnerables, especialmente de la protección de los menores". La ley derecho de familia: Revista jurídica sobre familia y menores, n. 23, pp. 41-54.

Splevins, Katie; Mireskandari, Shab; Clayton, Kimbra; Blaszczynski, Alex (2010). "Prevalence of adolescent problem gambling, related harms and help-seeking behaviours among an Australian population". Journal of gambling studies, v. 26, n. 2, pp. 189-204.

https://doi.org/10.1007/s10899-009-9169-1

Taylor, Charles R. (2017). "Native advertising: The black sheep of the marketing family". The international journal of advertising, v. 36, n. 2, pp. 207-209.

https://doi.org/10.1080/02650487.2017.1285389

Thomas, Samantha L.; Bestman, Amy; Pitt, Hannah; Cassidy, Rebecca; McCarthy, Simone; Nyemcsok, Christian; Cowlishaw, Sean; Daube, Mike (2018). "Young people's awareness of the timing and placement of gambling advertising on traditional and social media platforms: a study of 11-16-year-olds in Australia". Harm reduction journal, v. 15 , art. 51. https://doi.org/10.1186/s12954-018-0254-6

Tur-Viñes, Victoria; Núñez-Gómez, Patricia; Martínez-Pastor, Esther (2019). "YouTube, menores y cultura colaborativa. Revisión bibliográfica de la investigación académica". Historia y comunicación social, v. 24, n. 1, pp. 331-351. https://doi.org/10.5209/hics.64498

Unión Europea (2010). “Directiva 2010/13/UE del Parlamento Europeo y del Consejo de 10 de marzo de 2010 sobre la coordinación de determinadas disposiciones legales, reglamentarias y administrativas de los Estados miembros relativas a la prestación de servicios de comunicación audiovisual (Directiva de servicios de comunicación audiovisual)". Diario oficial, L 95, pp. 1-12, 15 abril.

https://eur-lex.europa.eu/legal-content/ES/TXT/?uri=CELEX:32010L0013

Unión Europea (2018). “Directiva (UE) 2018/1808 del Parlamento Europeo y del Consejo de 14 de noviembre de 2018 por la que se modifica la Directiva 2010/13/UE sobre la coordinación de determinadas disposiciones legales, reglamentarias y administrativas de los Estados miembros relativas a la prestación de servicios de comunicación audiovisual (Directiva de servicios de comunicación audiovisual), habida cuenta de la evolución de las realidades del mercado". Diario oficial, L 303, 28 noviembre, pp. 69-92.

https://eur-lex.europa.eu/legal-content/ES/TXT/HTML/?uri=CELEX:32018L1808\&from=ES

Wu, Katrina (2016). "YouTube marketing: Legality of sponsorship and endorsements in advertising". Journal of law, business \& ethics, v. 59, pp. 59-91.

https://www.scmv.com/_images/content/YouTube-Marketing_Katrina-Wu_stamped.pdf

Wunderman Thompson (2019). Generation alpha: Preparing for the future consumer. https://gertkoot.files.wordpress.com/2019/10/wtc-generation-alpha-2019.pdf

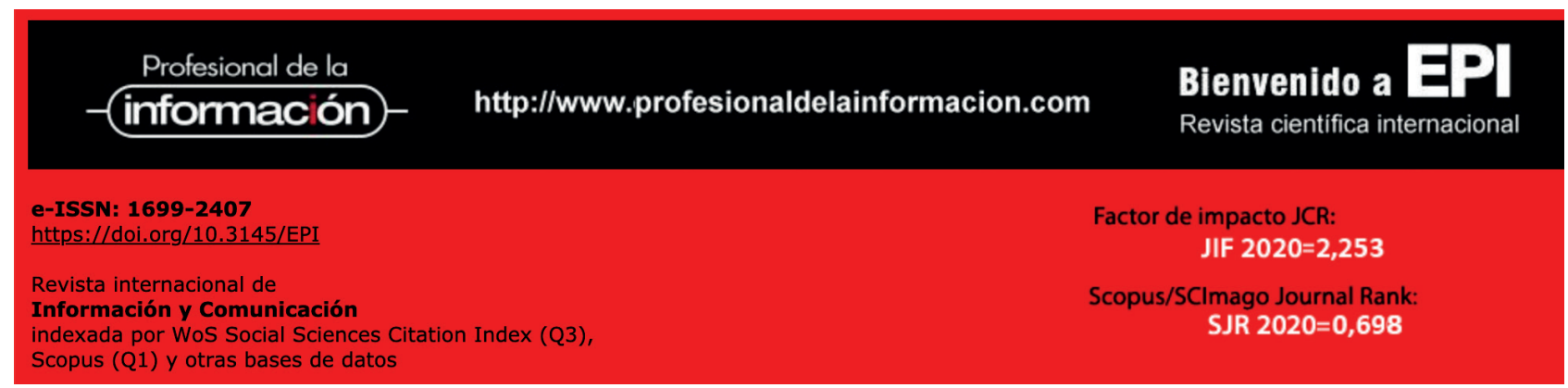

